\title{
Maize network analysis revealed gene modules involved in development, nutrients utilization, metabolism, and stress response
}

\author{
Shisong $\mathrm{Ma}^{1 *} \mathrm{D}$, Zehong Ding ${ }^{2}$ and Pinghua $\mathrm{Li}^{3^{*}}$
}

\begin{abstract}
Background: The advent of big data in biology offers opportunities while poses challenges to derive biological insights. For maize, a large amount of publicly available transcriptome datasets have been generated but a comprehensive analysis is lacking.

Results: We constructed a maize gene co-expression network based on the graphical Gaussian model, using massive RNA-seq data. The network, containing 20,269 genes, assembles into 964 gene modules that function in a variety of plant processes, such as cell organization, the development of inflorescences, ligules and kernels, the uptake and utilization of nutrients (e.g. nitrogen and phosphate), the metabolism of benzoxazionids, oxylipins, flavonoids, and wax, and the response to stresses. Among them, the inflorescences development module is enriched with domestication genes (like ral, bal, gt1, tb1, tga1) that control plant architecture and kernel structure, while multiple other modules relate to diverse agronomic traits. Contained within these modules are transcription factors acting as known or potential expression regulators for the genes within the same modules, suggesting them as candidate regulators for related biological processes. A comparison with an established Arabidopsis network revealed conserved gene association patterns for specific modules involved in cell organization, nutrients uptake \& utilization, and metabolism. The analysis also identified significant divergences between the two species for modules that orchestrate developmental pathways.
\end{abstract}

Conclusions: This network sheds light on how gene modules are organized between different species in the context of evolutionary divergence and highlights modules whose structure and gene content can provide important resources for maize gene functional studies with application potential.

Keywords: Comparative genomics, Gene network analysis, Maize development, Maize metabolism pathways, Plant nutrient uptake and utilization

\section{Background}

Advances over the past two decades have generated numerous transcriptome datasets. Increasingly, ever more complete transcriptome data can be merged and integrated with gene and genome structures. They provide unbiased snapshots of gene expression dynamics within

\footnotetext{
* Correspondence: sma@ustc.edu.cn; pinghuali@sdau.edu.cn

${ }^{1}$ School of Life Sciences, University of Science and Technology of China, Hefei, Anhui, China

${ }^{3}$ State Key Laboratory of Crop Biology, College of Agronomy, Shandong Agricultural University, Tai'an, Shandong, China

Full list of author information is available at the end of the article
}

organisms under various conditions. While cell-, organ-, or condition-specific expression profiles abound, it remains a key challenge to deduce the underlying gene regulatory circuits that control and give rise to the observed gene expression dynamics. To address this, gene network analysis has emerged as a tool that can filter and refine the analysis of large gene expression datasets. Such gene networks consist of genes (nodes) and connections (edges) between genes that represent coexpression dynamics or association patterns underlying the expression data. According to a 'guilt-by-association'

(c) The Author(s). 2017 Open Access This article is distributed under the terms of the Creative Commons Attribution 4.0 International License (http://creativecommons.org/licenses/by/4.0/), which permits unrestricted use, distribution, and reproduction in any medium, provided you give appropriate credit to the original author(s) and the source, provide a link to the Creative Commons license, and indicate if changes were made. The Creative Commons Public Domain Dedication waiver (http://creativecommons.org/publicdomain/zero/1.0/) applies to the data made available in this article, unless otherwise stated. 
paradigm, connected genes may have similar functions, be part of the same complex or pathway, or participate in the same signaling circuits [1]. Gene networks can assign putative functions to unknown genes based on functions revealed by their associates, or to identify novel genes for existing pathways [2, 3].

Different from random networks, gene networks generally identify gene modules categorizing and tracing groups of highly inter-connected genes that share similar expression patterns and, often, are recognizable by their relationship to a function in a particular biological process. Each module can be viewed as a unit in control of one or several biological functions. As such, modules identify and bring together segments of a biological system. Gene network analysis has been used to detect gene modules associated with, for example, human diseases or plant seed germination, and to study the transcriptome landscapes and gene module organization in yeasts, plants, and animals [4-10].

Gene networks derived from microarray data have been described for plant species such as Arabidopsis, maize, and rice $[6,8,11-13]$. These networks have been constructed via a variety of approaches that employed different ways to measure interactions between genes. Most common are co-expression networks that utilize the Pearson correlation coefficient (PCC) to measure expression similarity between genes, where gene pairs with PPC larger than a chosen threshold value are considered to interact with each other. Examples included two Arabidopsis networks: one identified clusters of genes involved in processes such as photosynthesis, vitamin metabolism, or cell cycle-regulation, while a second network revealed groupings with cellular organelles and tissue-specific functions $[8,11]$. Rice and maize networks were also assembled via the Weighted Gene Coexpression Network Analysis (WGCNA) method, which utilizes a power function of $\mathrm{PCC}$ to assess expression similarity $[6,12-14]$. Specifically, Downs et al. used WGCNA to construct a maize developmental gene co-expression network that captured modules with tissue and developmental stages specificity, while Ficklin and Feltus compared WGCNA networks from maize and rice to identify conserved modules [6, 13].

Yet another way to approach co-expression network analysis uses the graphical Gaussian model (GGM), which utilizes partial correlation (Pcor) to identify association relationships between genes [15-17]. Significantly, Pcor determines the correlation that remains between two genes after removing the effects of all other genes. Pcor measures direct association between genes, while PCC often fails to differentiate between direct and indirect associations $[15,16]$. Thus, Pcor is deemed as a better metric than PCC for gene network analysis $[16,18]$. However, the utilization of GGM has been impeded by a requirement that the number of samples must be far larger than the number of genes. The original design was able to calculate Pcor data among a few thousand genes only [16]. Previously, we developed a random samplingbased method to overcome this obstacle and constructed the first genome-wide GGM network for Arabidopsis, followed by an updated network model termed AtGGM2014 [7, 17]. Compared to other networks, AtGGM2014 contained more genes and identified additional modules participating in a large variety of plant processes, like development, metabolism, response to stresses, and response to hormones [7]. For example, among many informative gene modules, it included hormonal signaling modules for phytohormones like auxin, abscisic acid, jasmonic acid, gibberellins, cytokinins, ethylene, and salicylic acid, demonstrating the network's potential to facilitate systems biology studies on Arabidopsis gene functions.

More recently, a large collection of RNA-Seq based maize gene expression datasets have been generated by different groups and deposited in the public domain. Among these datasets are a gene expression atlas for 79 maize tissues $[19,20]$, as well as expression datasets for specific organs like inflorescences [21], leaves [22], ligules [23], embryos and endosperms [24], and transcriptome datasets for different compartments in the endosperm $[25,26]$. Others resulted from monitoring maize responses to abiotic stresses [27, 28], fungal infections [29], and different nutrition regimes [30]. These datasets provide extremely valuable information for maize functional genomics research. A maize RNA-Seqbased gene network focused exclusively on development has been constructed from expression data of 23 different tissues, which identified 19 gene modules via the WGCNA method [31]. However, to our knowledge, missing so far is a comprehensive gene network analysis that combines the wealth of many different maize datasets and merges them into an inclusive network to outline future research opportunities.

Here, we constructed a maize GGM gene coexpression network using expression data from 787 RNA-Seq runs deposited in the NCBI SRA database. 964 gene modules were identified from this network, highlighting functions in various cell organization, development, nutrients, metabolism, and stress responses pathways. As examples, we describe in detail modules involved in the development of inflorescences, ligules, and kernels, the uptake and utilization of nitrogen and phosphate, the metabolism of benzoxazionids, oxylipins, flavonoids and wax, and the response to heat stress, endoplasmic reticulum (ER) stress, and fungal infections. These modules provide a general picture for the relevant biological processes and identified both known genes as well as potential, so far unconnected, candidate genes 
for future functional studies. Importantly, many of these modules contain transcription factor genes that act as potential gene expression regulator for the genes within the same modules. In addition, the maize network has been compared to a previous published Arabidopsis network [7]. This juxtaposition revealed conserved as well as diverging modules in the two species. The identified gene modules were further used to analyze a dataset on a maize leaf developmental series [22], demonstrating the usefulness of this network for systems biology analysis.

\section{Results}

\section{Overview of the maize GGM gene network}

A maize gene co-expression network based on GGM was constructed using maize RNA-Seq transcriptome datasets deposited in the NCBI Sequence Read Archive (SRA) database. The publicly available raw data files (.sra) were downloaded, mapped against the maize reference genome (AGP_v3.22), and processed into gene expression values. After removing files with mapping rates $<70 \%, 787$ RNA-Seq runs from 36 different studies (Additional file 1: Table S1) were retained and their Fragments Per Kilobase of transcript per Million mapped reads (FPKM)-normalized gene expression values were combined into a large gene expression matrix. These datasets monitor maize transcriptomes from various tissues and developmental stages, after a variety of biotic and abiotic stress treatments, or from well-characterized mutants. The genes with maximum FPKM values $<20$ were filtered out, resulting in a gene expression matrix that included 29,316 maize genes (rows) and 787 RNA-Seq runs (columns). Similar to other RNA-Seq data, these maize RNA-Seq data showed a mean-variance dependency [32], i.e. genes with higher mean expression values were more likely to have larger variances. The gene expression matrix was transformed via log-transformation to reduce such mean-variance dependency (Additional file 2: Fig. S1), making the dataset more suitable for correlation analysis [32]. Logtransformation has been used before for gene coexpression and gene clustering analysis with RNA-Seq data [33-40]. The log-transformed gene expression matrix was then used for the calculation of partial correlation coefficients (Pcor), following a procedure described before [17]. Figure 1a shows the distribution of the Pcors between all genes pairs, $98.4 \%$ of which are in the range between -0.01 and 0.01 . The gene pairs with $\mid$ Pcor $\mid>=0.035$ (pValue $=2.22 \mathrm{E}-16)$ were kept for network construction. Additionally, Pearson Correlation Coefficients (PCC) was also calculated for all gene pairs and those with $|\mathrm{PCC}|<0.35$ were removed, reasoning that a low PCC very likely indicates independence between genes. As a result, 123,093 genes pairs with Pcor $>=0.035$ and PCC $>=0.35$ and 573 gene pairs with Pcor $<=-0.035$ and $\mathrm{PCC}<=-0.35$ were selected for gene network construction (Additional file 3: Table S2).

This reasoning resulted in a maize GGM network including 20,269 genes and 123,666 co-expressed gene pairs $(0.06 \%$ of all possible gene pairs). The clustering coefficient $(C)$ of the network is 0.209 , while the expected $C$ of a random network of the same size is only 0.0006 [41]. Since $C$ measures a network's potential modularity [42], the large $C$ of the maize GGM network indicates high characteristics of modularity. Indeed, a network clustering procedure using the MCL program [43] identified 964 gene modules that contain 5 or more genes each, and these 964 modules encompass 16,668 genes in total. These modules can be viewed as co-expression modules, whose genes share similar
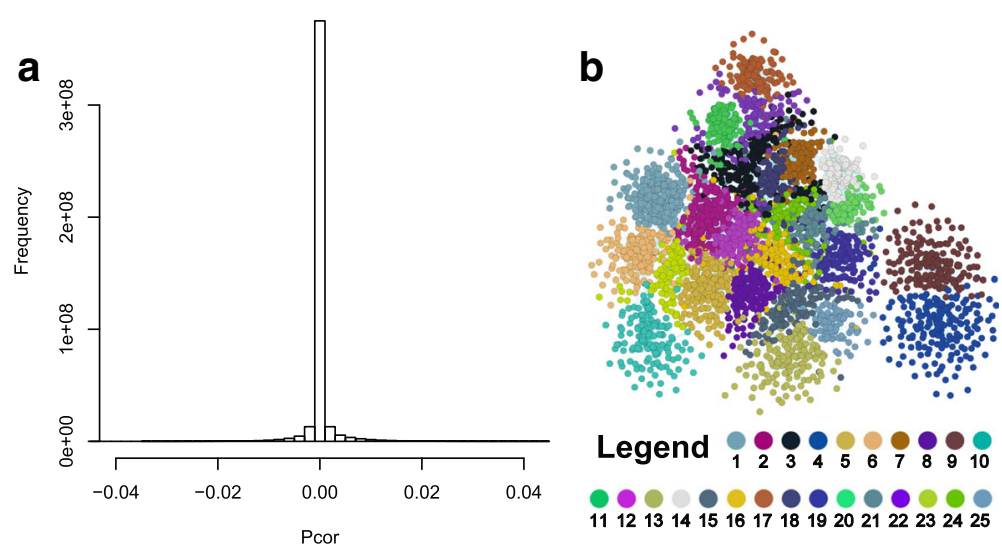

Fig. 1 An overview of the maize GGM network. a A histogram showing the distribution of the partial correlation coefficients of all the gene pairs. Most genes pairs have their Pcors in the range between -0.01 and 0.01 , indicating no interactions. b A sub-network for the largest 25 modules identified from the network. Each dot represents a gene, and a connection between two genes indicates interaction between the two. The color of a node indicates its module identity, as shown in the legend 
co-expression patterns and, according to the 'guilt-byassociation' paradigm, might have similar functions or participate in the same pathways. The rest 3601 genes were assigned to small modules with 4 or less genes, which were not considered in further analysis. Within our network, the largest 222 modules containing between 15 and 306 genes (Fig. 1b, Additional file 4: Table S3). Based on Gene Ontology (GO) enrichment analysis, many of these modules fall into 5 distinct categories, with functions in: i. Cell organization; ii. Development; iii, Nutrient uptake \& utilization; iv. Metabolism, including primary \& secondary metabolism; and v. Stress responses (Table 1 \& Additional file 1: Table S4). Modules for cell organization and primary metabolism include those for cell cycle regulation (Module \#60), DNA replication (\#64), cytoskeleton organization (\#69), nucleosome assembly (\#49), photosynthesis (\#20 and 129), and mitochondria-related functions (\#14 and 86) (Table 1). Several of these modules are highly conserved when compared to similar modules reported in a published Arabidopsis network, AtGGM2014 [7].

Shown in Fig. 2a is Module \#129 for photosynthesis, and Fig. $2 \mathrm{~b}$ is a subnetwork for Arabidopsis homologues of the genes in this module extracted from the Arabidopsis network AtGGM2014. The similarity of the structure and gene content in both species is significant. To enable direct comparison between the two networks, we consider a maize gene to have conserved interactions between the two networks if the maize gene and its Arabidopsis homologue share at least one homologous neighboring gene across the networks (Fig. 2c). According to this criteria, $9.7 \%$ of the genes in the whole maize network have conserved interactions. In contrast, $65 \%$ of the genes in Module \#129 show conserved interactions in Arabidopsis, much higher than the network-wide level, indicating high conservation for the genes within this module. Within the modules for cell organization and mitochondria-related functions, $19 \%$ to $80 \%$ of the genes also revealed conserved interactions. We will describe modules in other GO categories with varied degrees of conservation between the two species.

\section{Gene modules revealing developmental features}

Maize plant architecture is a major yield-determining trait. Our gene network identified three particularly relevant modules. Module \#16 is enriched with genes involved in the development of ears and tassels, and contributes to shaping the maize inflorescences architecture (Fig. 3a, Table 1, and see Additional file 4: Table S3 for the complete list of genes within this module and the modules discussed below). According to published gene expression datasets on maize development [19-21, 23-26], the 139 genes within this modules are mainly expressed in ears, tassels, and immature cobs (Additional file 5: Fig. S2), and 56 of them encode transcription factors (TF). Included within the module are ra1 (ramosa1) and ba1 (barren stalk1), two TF genes with opposite roles in tassels development $[44,45]$. Maize recessive mutants of $r a 1$ and $b a 1$ have increased and zero number of tassel branches respectively. A number of genes for the development of ears and tassels were included as well: ra3 (ramosa3), sk1 (silkless ears1), spi1 (sparse inflorescence1), tb1 (teosinte branched1), gt1 (grassy tillers1), and bd1 (branched silkless1), [46-51]. Also contained is tga1 (teosinte glume architecture1), a gene conferring the naked kernel phenotype in maize [52]. Uncharacterized genes within the module include GRMZM2G022606 and GRMZM2G026556, two genes homologous to $B O P 2$ in Arabidopsis. In Arabidopsis, $B O P 1, B O P 2$, and PUCHI (a $b d 1$ homologue) redundantly promote floral meristem fate [53], raising the possibility that the two maize genes might have a similar function. Also uncharacterized are ereb161 and nactf114, homologous to Arabidopsis genes ANT and CUC3 that regulate ovule and embryonic apical meristem formation, respectively [54, 55]. In addition, the module contains other potential development related genes as well, including 8 YABBY, 4 AP2/EREBP, 3 SHI RELATED SEQUENCE (SRS), and 3 SQUAMOSA PROMOTER BINDING PROTEIN (SBP) type TF genes. The genes in Module\#16 could possibly form an elaborate yet balanced network orchestrating maize inflorescences development. And at least five of them, $r a 1, b a 1, g t 1, t b 1$, and $t g a 1$, have been subjected to selection during maize domestication and were designated as domestication genes [44, 45, 47, 51, 52, 56]. Interestingly, when compared to the Arabidopsis network, only 18 of the 139 genes within the maize module show conserved interaction(s), among them 7 YABBY TFs. Thus, only $8.4 \%$ of the genes revealed conserved interaction(s) when the YABBY genes are not considered. This indicates extensive pathways re-shuffling between the two species for inflorescences development.

Ligules are fringe-like tissues located at the junction of the leaf blade and leaf sheath. In maize ligules control leaf angles and affect vegetative architecture [57, 58]. Two modules involved in ligules development were identified. Module \#48 (Fig. 3b, Table 1 \& Additional file 4: Table S3) is specifically expressed in the pre-ligule region of the leaf primordia (Additional file 5: Fig. S2). A key gene within the module is lg1 (liguleless1), encoding a SBP TF that acts as a mater regulator of ligule development [58]. The recessive $\lg 1$ mutations in maize erases ligules and renders leaves more upright compared to wild type leaves [57]. Interestingly, the genes within this module have their promoters enriched with a SBP TF binding motif "CGTAC" (pValue = 1.04E-6) [59], indicating they might be targets of Lg1. Two other SPB genes, $s b p 3$ and $s b p 28$, are also included within the module, although their functions remain uncharacterized. 


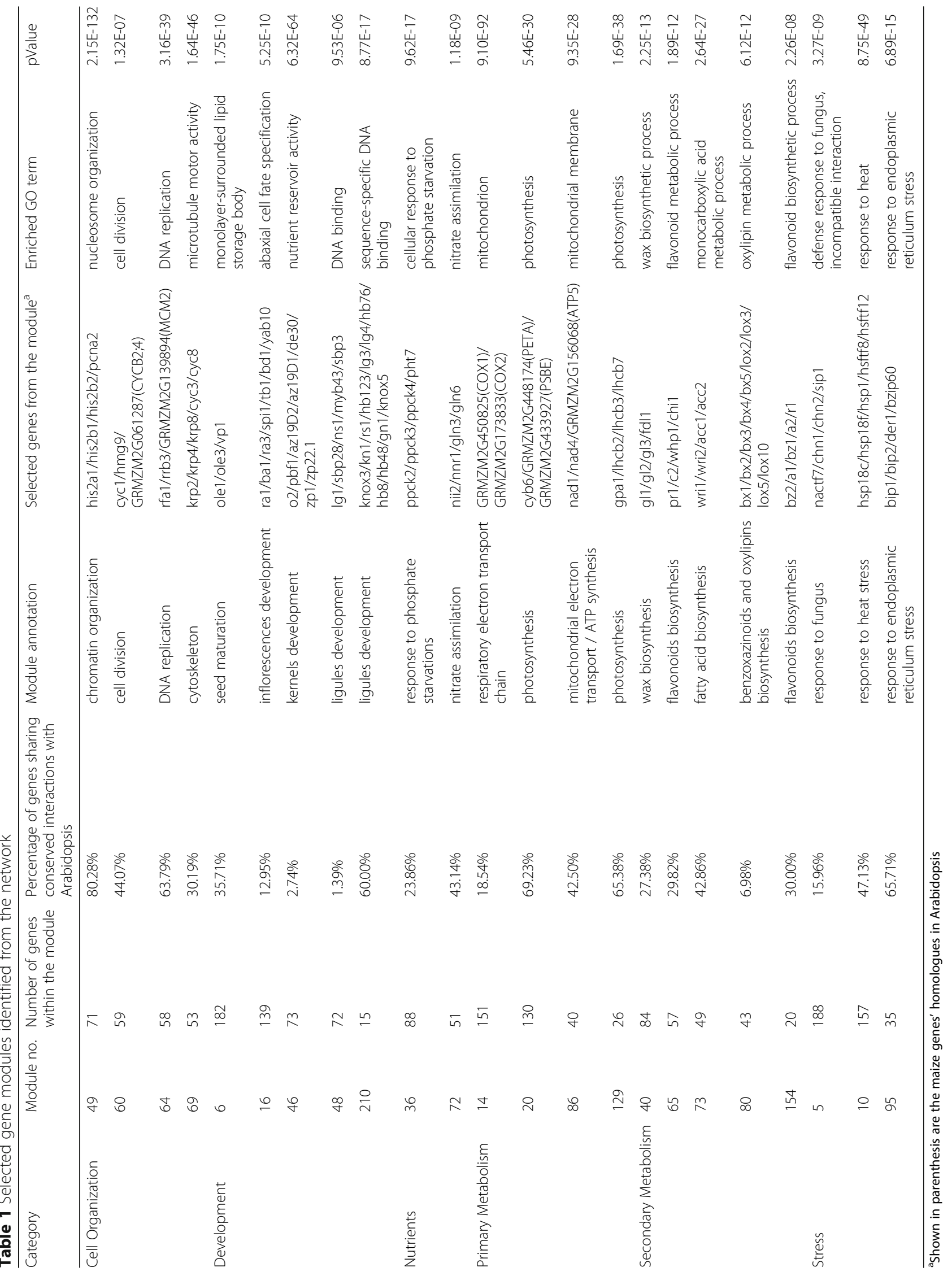



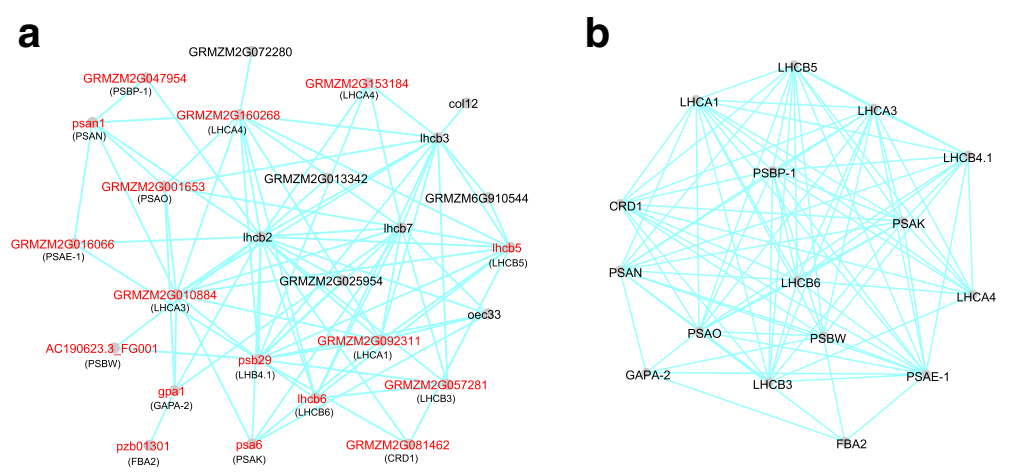

C

Maize network

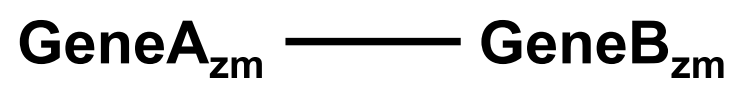

homologous

homologous

\section{GeneA $_{\text {at }} \longrightarrow$ GeneB $_{\text {at }}$}

\section{Arabidopsis network}

Fig. 2 Network comparison between maize and Arabidopsis. a A maize module functioning in photosynthesis. Red color indicates the gene has conserved interaction(s) in the Arabidopsis network. The maize genes' Arabidopsis homologues are shown in parenthesis. b An Arabidopsis sub-network for the homologues of the maize genes in (a). c A maize gene is considered to have conserved interaction(s) in Arabidopsis if its homologues and at least one of its interactors' homologue also interact within the Arabidopsis network

Other potential development regulators included $m y b 44$, a homologue of Arabidopsis LOF1 that functions in organ boundary specification [60], GRMZM2G480687, encoding a MEMBRANE-ASSOCIATED KINASE REGULATOR (MARK) proteins, and GRMZM2G145909, homologous to an Arabidopsis atypical bHLH gene IBL1. MARKs and atypical bHLH TFs in Arabidopsis participate in developmental processes mediated through brassinosteroids (BR) $[61,62]$, while BR-signaling also regulates ligules development in maize [63]. Module \#210 contains 15 genes, eight of which encode TFs in the KNOX family (Table 1 \& Additional file 4: Table S3). Among these TFs are gn1 (gnarley1), kn1 (knotted1), rs1 (rough sheath1), lg3 (liguleless3), and lg4 (liguleless4), none of which show any expression in the pre-ligule regions of the wild type plants (Additional file 5: Fig. S2). However, ectopic expression of any of these genes in their corresponding dominant mutant background affects and distorts leaf and ligule development [64-66]. It remains to be tested if the other 3 KNOX TFs within the module have similar functions and if and how these TFs function together to regulate ligules development.

Kernels development represents yet another critical process determining maize grain yield and quality. Five relevant gene modules are identified. Among them,
Module \#46 (Fig. 3c, Table 1 \& Additional file 4: Table S3), including 73 genes, is specifically expressed in the endosperm (Additional file 5: Fig. S2) and enriched with genes indicating nutrient reservoir activity (GO pValue $=6.32 \mathrm{E}-64)$. The module contains 16 genes encoding $\alpha-, \delta$-, or $\gamma$-zein proteins, the major seed storage proteins in maize, and 4 genes for starch biosynthesis (bt1, bt2, sh2, and wx1) [67, 68]. Notably, also included are a bZIP TF gene o2 (opaque endosperm2) and a Dof TF gene pbf1 (prolamin-box binding factor1), two master regulators of zein gene expression $[69,70]$. It is recognized that within the maize network transcription factors and their target genes are often contained within the same modules, providing an edifying way to identify those modules' expression regulator(s). Module \#42 includes other TF genes as well, such as ereb167, platz12, nrp1, nactf130, as potential transcription regulators. Module \#6 is expressed in both embryo and endosperm tissues at late developmental stages (Additional file 5: Fig. S2) and enriched with genes functioning in seed maturation (pValue $=7.39 \mathrm{E}-6$ ) The module includes many lipid storage genes (e.g. oleo$\sin 1)$, desiccation tolerance genes (e.g. genes encoding late embryogenesis abundant proteins), and the TF gene $v p 1$ (viviparous1), a master regulator of seed maturation and 


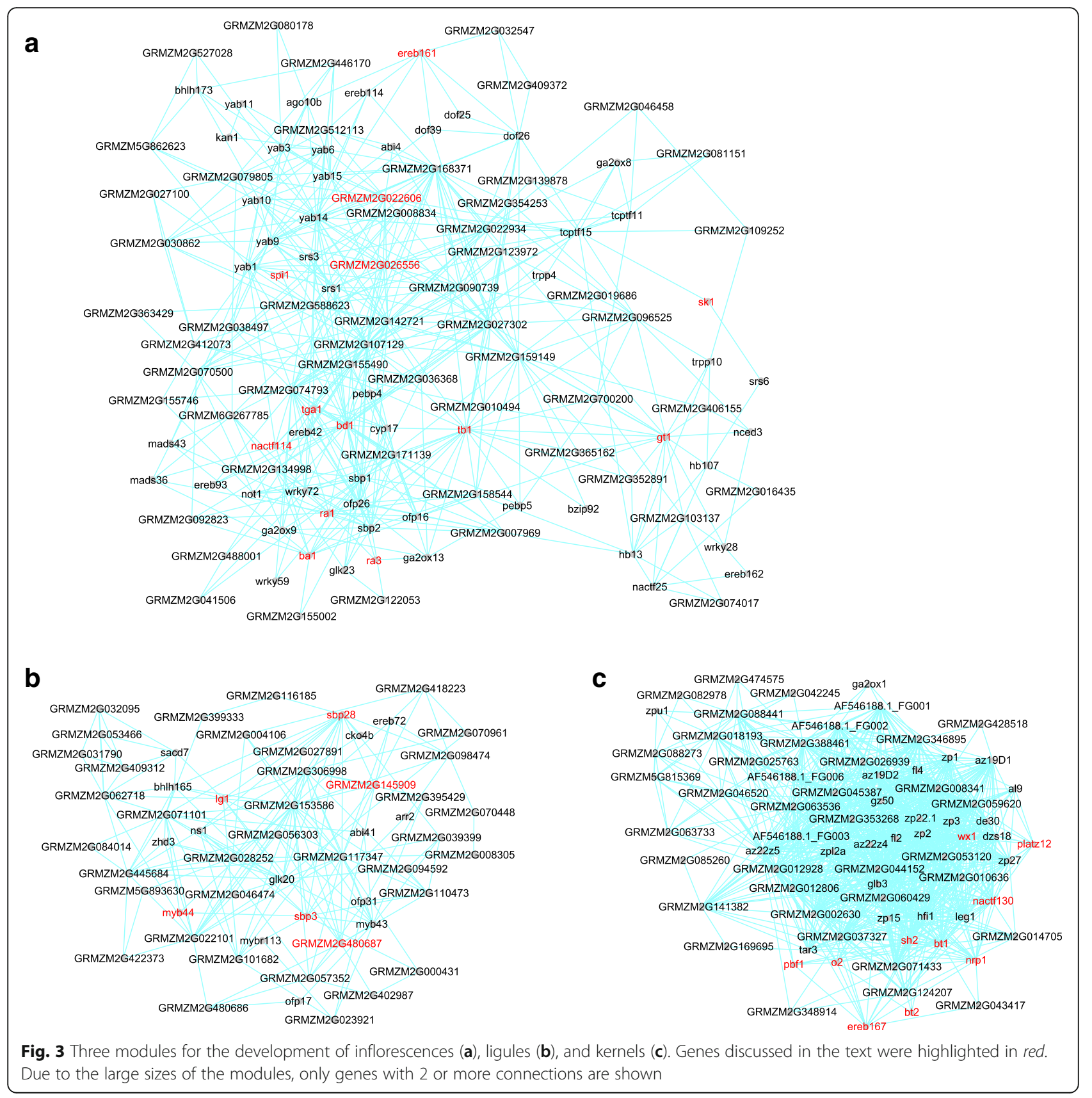

dormancy (Additional file 4: Table S3) [71]. 36\% of the genes within this modules possess conserved interactions when compared with the Arabidopsis network, including the key seed development genes like $v p 1$, ole 1, ole 3 , and $m l g 3$. Additional modules were recovered with specific expression in different compartments of the maize endosperm, such as the basal endosperm transfer layer (BETL) (\#11), the embryo-surrounding region (ESR) (\#32), and the placento-chalazal region (PC) (\#53) (Additional file 6: Fig. S3), similar to a previous report [26]. These examples indicate that our network delineates different modules corresponding to different functional domains of kernels development and provides a general picture of the process.

Other modules were identified that draw attention to the development of other tissues and organs (Additional file 1: Table S4, Additional file 7: Fig. S4), such as anthers (\#3, 17 and 22), meiotic tassels (\#18), roots (\#30), carpels (\#92), Casparian strip (\#76), and epidermal cells (\#155). Furthermore, identified were modules for primary (\#543) and secondary cell wall biosynthesis (\#13), and for the signaling pathways of development related 
hormones, such as auxin (\#158) and cytokinins (\#183) (Additional file 1: Table S4). These modules are valuable resources for future functional studies on distinct and related developmental processes.

\section{Modules for nutrients uptake and utilization}

Nutrient use efficiency is a key objective for crop improvement. Modules can be pinpointed from the maize network as functioning in nitrogen, phosphate, iron, and sulfate uptake and utilization. In general, these modules are conserved between maize and Arabidopsis. For example, Module \#72 (Fig. 4a, Table 1 \& Additional file 4: Table S3) shows enrichment for nitrate-responsive genes that encode the key enzymes for reducing and incorporating nitrate into glutamine, including nitrate reductases (GRMZM5G878558 and nnr1), nitrite reductase (nii2),

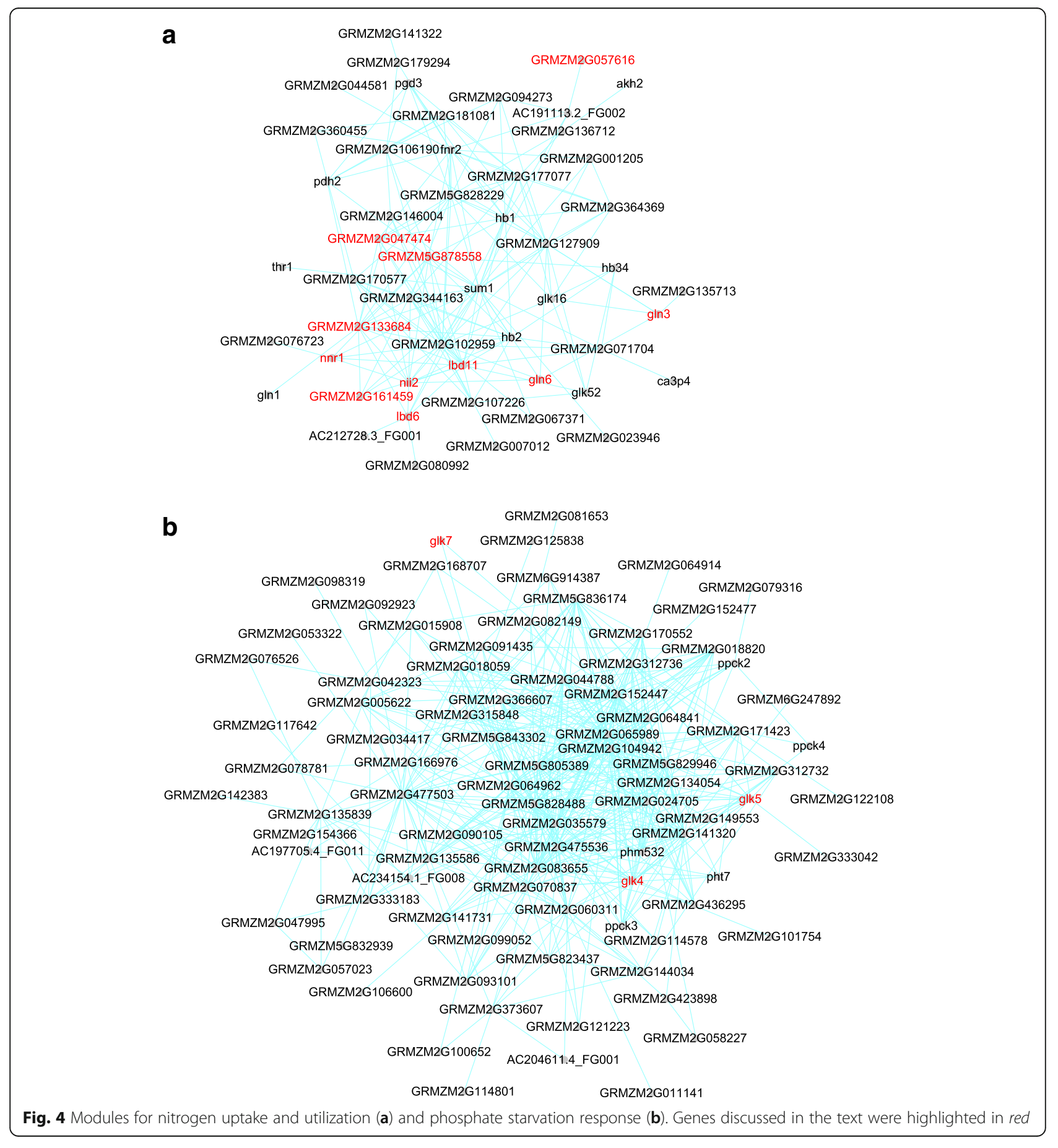


and glutamine synthetase $(g \ln 1, g \ln 3, g \ln 6)$ [72-74]. Also contained are GRMZM2G161459 and GRMZM2G057616, homologues of the Arabidopsis genes NRT1.1 (encoding a nitrate transporter and sensor) and $C L C-A$ (encoding a vacuole nitrate transporter required for high nitrate uptake capacity) [75, 76]. Compared with the Arabidopsis network, 22 out of the 51 genes in this module showed conserved interaction(s). Among them are two unknown genes, GRMZM2G047474 and GRMZM2G133684, whose homologues in Arabidopsis AT5G39590 (encoding a TLD domain containing protein) and AT5G62720 (encoding an integral membrane HPP family protein) are also included in an Arabidopsis nitrate-responsive module but they remain uncharacterized. Their appearance in nitrate responsive modules in both species strongly suggests functions in nitrate sensing, uptake and/or utilization. Also conserved are two uncharacterized LOB-type TF genes $l b d 6$ and $l b d 11$, homologous to one Arabidopsis nitrate response regulator gene LBD37 [77], indicating $l b d 6$ and $l b d 11$ arguably could have similar functions in maize. Additionally, the maize module includes genes encoding G2-like, HB, and $\mathrm{C} 2 \mathrm{H} 2$ type $\mathrm{TFs}$, whose functions in nitrate response have not yet been tested.

Module \#36 includes genes involved in the phosphate starvation response (pValue $=9.62 \mathrm{E}-17)($ Fig. $4 \mathrm{~b}$, Table 1 \& Additional file 4: Table S3). The maize module includes homologues of Arabidopsis phosphate starvation response genes, such as SPX2, SPX3, SQD1, $S Q D 2, M G D 2$, and PS2 [78], although their functions have not been characterized in maize. A P1BS motif "GNATATNC", the binding site of the Arabidopsis G2-like transcription factor PHR1, a master regulator of phosphate starvation response gene expression [79], is enriched in the promoters of the genes in this module ( $\mathrm{pValue}=9.40 \mathrm{E}-24)$. Interestingly, the maize module contains three G2-like TFs, glk4, glk5, glk7, which could also act as master regulators.

Maize modules involved in the uptake and utilization of iron (\#43) and sulfate (\#79) were also identified (Additional file 1: Table S4). It should be noted that, compared to Arabidopsis, fewer transcriptome datasets are available for maize. As more data become available, more maize modules for nutrient uptake and usage should be revealed in future analysis.

\section{Modules for metabolic processes}

Gene modules were identified for various processes in maize metabolism. In addition to those involved in primary metabolisms, numerous modules functioning in secondary metabolism emerge as well. Some of these modules are unique to maize, while others share considerable similarities between Arabidopsis and maize. Among them, genes in Module \#80 (Fig. 5a, Table 1 \& Additional file 4: Table S3) provide functions in the production of benzoxazinoids and oxylipins, which are secondary metabolites effective in anti-herbivore defense [80]. Benzoxazinoids are mainly found in Poaceae species, including maize, wheat, and rye, but appear only infrequently in dicots and are absent in Arabidopsis [81]. Module \#80 includes most known genes of the maize benzoxazinoids biosynthesis pathway - $b x 1$ (benzoxazinless1), $b x 2, b x 3$, $b x 4, b \times 5, b x 6$, and $b \times 8$ that form a gene cluster in chromosome 4 , and $b \times 9$ in chromosome 1 [81]. Interestingly, none of these $b x$ genes share any conserved interactions with the Arabidopsis network, consistent with the absence of benzoxazinoids biosynthesis pathway in Arabidopsis. Additionally, the module is enriched with oxylipins biosynthesis genes (pValue $=2.22 \mathrm{E}-10$ ), such as lox2, lox3, lox5, lox6, and lox10. The inclusion of both benzoxazinoids and oxylipins biosynthesis genes implies this module's function in defense response.
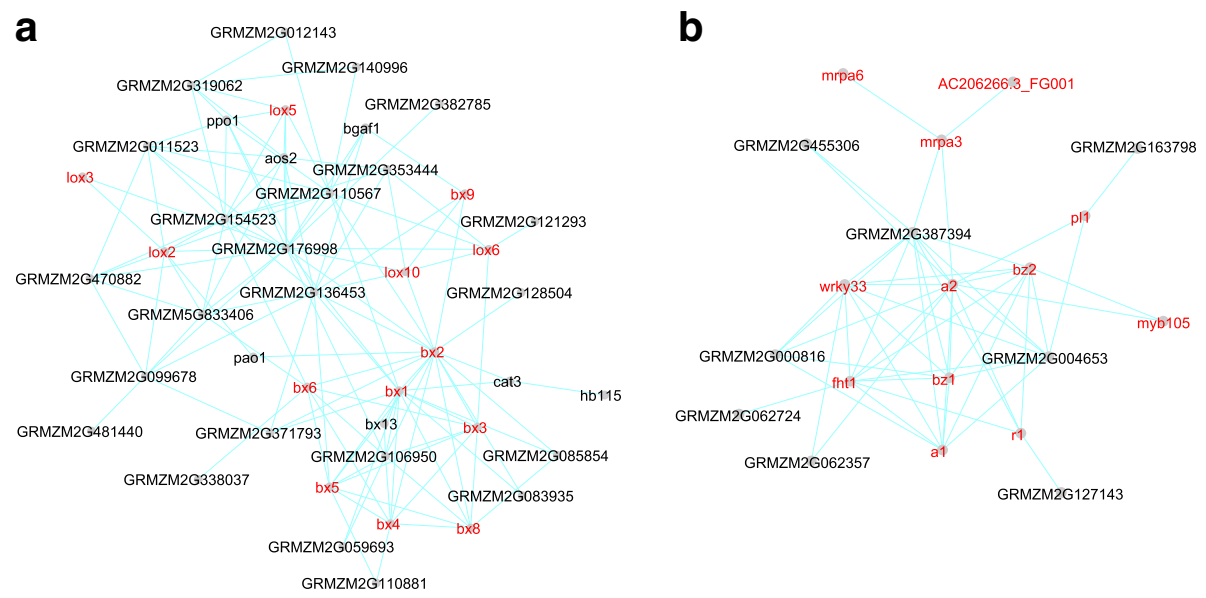

Fig. 5 Modules for the biosynthesis of benzoxazinoids and oxylipins (a) and flavonoids (b). Genes discussed in the text were highlighted in red 
Module \#154 (Fig. 5b, Table 1 \& Additional file 4: Table S3) is enriched with flavonoids biosynthesis pathway genes (pValue $=2.26 \mathrm{E}-08$ ), including fht1, a1, a2, $b z 1, b z 2$ [82]. The module also contains pl1 (purple plant1) and $r 1$ (colored1), two TF genes controlling anthocyanin biosynthesis [82], and two potential regulatory TFs myb105 and wrky33. In Arabidopsis, TTG2, a homolog of wrky33, regulates tannin level in the seed coat [83], while the function of maize wrky33 remains to be tested. The maize module also includes the gene mrpa3, encoding a tonoplast-localized anthocyanin transporter [84], and two uncharacterized transporter genes mrpa6 and AC206266.3_FG001. In addition to Module \#154, involvement in flavonoids biosynthesis is indicated for Module \#65 as well.

Waxes, deposited on the aerial surface of plants as a water-proof layer, are essential for plants in that they not only significantly limit water loss, but also counteract environmental stresses [85]. Module \#40 (Additional file 8: Fig. S5, Table 1 \& Additional file 4: Table S3) of the maize network is enriched with wax biosynthesis genes (pValue $=2.25 \mathrm{E}-13$ ), i.e. $g l 1, g l 2$, and $g l 3$ [86]. Among the 84 genes within this module, 23 have conserved interactions when compared with the corresponding Arabidopsis network. Conservation extends to uncharacterized genes that are homologous to Arabidopsis wax biosynthesis genes like KCS1, KCS6, KCS12, CER3, and LACS1 [86]. Another conserved gene pair are fdl1 (fused leaves1) in maize and MYB94 in Arabidopsis, homologous to each other, both identified recently as TF regulators of wax biosynthesis $[87,88]$. The maize module also contains gl3 (glossy3), another MYB TF as a master regulator of wax production [89]. Other potential TF regulators within the module include 3 AP-EREBP type TFs, ereb12, ereb60, and ereb143. Among them, ereb60 shows homology to Arabidopsis WRI1 that regulates the accumulation of fatty acids - precursors for wax biosynthesis [90]. Additionally, another related module for fatty acid biosynthesis (\#73) was also identified from the network (Table 1).

In addition to benzoxazinoids, oxylipins, flavonoids, wax, and fatty acids, modules were also identified for the metabolism of suberin (\#42), trehalose (\#61), glucose (\#234), glucan (\#278), and lignins (\#712) (Additional file 1: Table S4). Based on these modules, promising candidate genes can be selected for future functional studies.

\section{Modules for stress responses}

Modules involved in abiotic stress responses were also identified. For example, the genes in Module \#10 (Additional file 8: Fig. S6, Table 1 \& Additional file 4: Table S3) show relationships to heat stress responses. Enriched are heat shock stress response genes
$(\mathrm{pValue}=8.75 \mathrm{E}-49) .74$ of the 157 genes within this module share conserved gene interaction(s) with an Arabidopsis heat shock related gene module [7]. The conserved genes include 6 heat shock transcription factor genes (hsft7/8/12/20/24) and a co-activator gene MBF1C (GRMZM2G051135), highlighting their overarching importance in regulating heat activated gene expression regulation. The splicing regulator genes $S R 45 a$ (GRMZM2G073567) and SR30 (GRMZM2G331811) are also included in the list of conserved genes, suggesting alternative splicing could play important roles in the heat shock response in both species. Similarly, Module \#95 (Additional file 8: Fig. S7, Table 1 \& Additional file 4: Table S3) is enriched with ER stress response genes (pValue $=6.89 \mathrm{E}-15) .23$ out of the 35 genes within the module shared conserved interactions with Arabidopsis, including bip1, bip2, pdi1, and der1 [91]. Interestingly, contained within the maize module is a putative master regulatory TF gene bzip60 [92], whose homologue in Arabidopsis, bZIP60, is a major regulator of the ER stress response [93], indicating bzip60 might have similar function in maize.

Also identified from the network were modules related to biotic stress responses. For example, Module \#5 (Additional file 8: Fig. S8, Table 1 \& Additional file 4: Table S3) is enriched with genes functioning in defense responses to fungal infections (pValue $=3.27 \mathrm{E}-09$ ), such as cta1, wip1, prp1, and tps6. It contains a NAC type TF gene nactf7, a homologue of the Arabidopsis NAC042 gene. In Arabidopsis, NAC042 is a master TF that regulates the biosynthesis of the anti-fungal compound camalexin [94]. Although maize does not produce camalexin, the inclusion of nactf7 in this anti-fungal module indicates that it may modulate other secondary metabolism processes to produce anti-fungal compounds. Indeed, within the module are many metabolism-related genes, including 9 genes encoding cytochrome P450 enzymes, whose roles in maize anti-fungal defenses remain to be studied. Interestingly, the module also encompasses genes for gibberellin biosynthesis ( $k s 1, k s 4, k o 2$, and cpps2), consistent with previous reports that infection by certain fungal pathogens upregulates gibberellin related genes in maize [95].

Additional defense related modules were identified from the network, for example Module \#2 and \#47 (Additional file 1: Table S4). These modules provide useful targets for future functional studies.

\section{Gene network comparison between maize and Arabidopsis}

The examples discussed above demonstrate that some maize gene modules are conserved between maize and Arabidopsis, while others display greater divergence. The percentage of genes with conserved interaction(s) 
ranged from $0 \%$ to $83 \%$ for different modules (Fig. 6, Additional file 1: Table S5). Among them, the cell organization related modules retain the highest degree of conservation, in particular those for DNA replication and nucleosome assembly. Many modules in the nutrient uptake, stress-response, and metabolism categories display conservation above the network-wide average level, except for Module \#80 with focus on benzoxazinoids and oxylipins biosynthesis. For the development modules, conservation varies significantly. Those involved in carpels, Casparian strip, epidermis, and cell wall development are conserved, all of which constitute the basic building blocks of the plant body. However, much more divergence is seen for modules for kernel/ seed metabolism, anthers, inflorescences structure, or root development. Such difference can be attributed to the obvious biological differences between the two species, which define development, growth habitus and structure defining the two species. Nevertheless, both differences and similarities of genes identified in our high-stringency module structure can provide clues about unidentified functions in either one of the two species. The monocot/dicot comparison may further be exploited for additional gains in knowledge.

\section{Gene expression dynamics of gene modules in maize leaves}

The maize gene modules identified from our network were used to re-analyze a previously published dataset that had measured transcriptomes from 15 segments of maize leaves, from the base to the tip, representing pronounced developmental gradients [22]. Owing to the pronounced differences in development and physiological functions in maize leaf segments, distinct expression dynamics are revealed in these modules. The average gene expression levels in each module for every segment was computed (Fig. 7). As expected, Module \#60, involved in cell cycle regulation, is mainly expressed in Segment 1 at the base of the leaves, where cell division is most active. Other modules with peak expression at the base include those for DNA replication (\#64), cytoskeleton organization (\#69), nucleosome assembly (\#49), ribosomal functions $(\# 125,140)$, plastid development (\#308), primary cell wall biosynthesis (\#543), and ER stress response (\#95). These modules appear to be involved in the early development and building of leaf cells, and high expression of ER related genes might be indicators of intense protein synthesis. Peak gene expression for four modules is observed in the mid part of the leaves (Segments 2 to 5), including those for the biosynthesis of secondary cell walls (\#13), waxes (\#40), suberin (\#42), and lignin (\#331), likely representing maturation of the leaf tissue. Module \#129, containing mainly light reaction-related photosynthesis genes, was highly expressed and peaked around Segments 9 and 10, which can be an indicator of overall light reaction intensity. Several modules functioning in carbohydrate metabolism or transport show peak expression at late stages (Segments 12 to 14), including \#61 for trehalose biosynthesis, \#278 for glucan metabolism, and \#105 for carbohydrate transport (containing genes such as sweet $13 a / b / c)$. Thus, combining the modular arrangements revealed by the gene network with detailed leaf segment RNA-Seq datasets provided a coherent and detailed picture of maize leaf development, maturation, and biochemical activities. The results were consistent with the previous report [22, 96], and similar analysis can be applied to other maize datasets as well.

\section{Discussion}

We report on the construction of a maize GGM gene co-expression network that includes 20,269 genes based on large-scale RNA-Seq transcriptome data. The resulting gene network was then analyzed and clustered via the MCL clustering algorithm [43]. Although the algorithm partitioned the network purely based on its topology, the analysis resulted in 964 distinct and informative gene modules that included functions in a

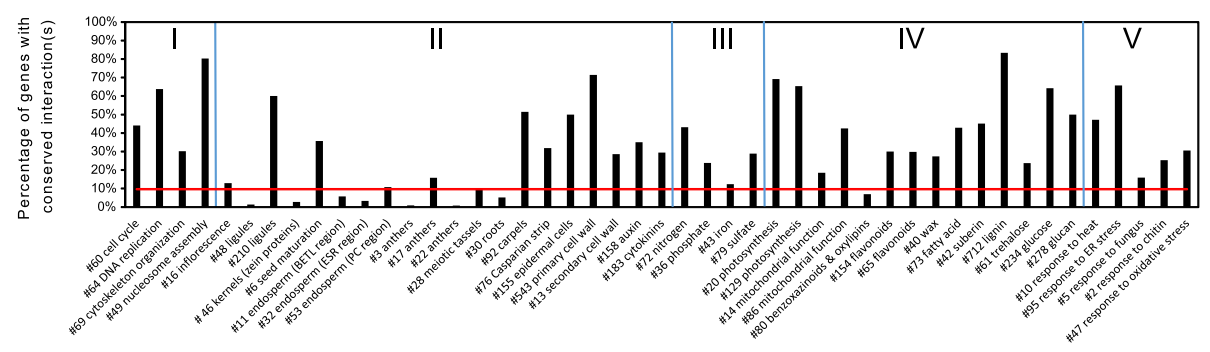

Fig. 6 Network comparison between maize and Arabidopsis. For selected maize gene modules, the percentage of genes with conserved interaction in Arabidopsis were shown. Modules are organization by 5 categories: I, cell organization; II, development; III, nutrient uptake \& utilization; IV, metabolism; $V$, stress response. The red line indicates the percentage of genes with conserved interaction(s) in the whole maize network 

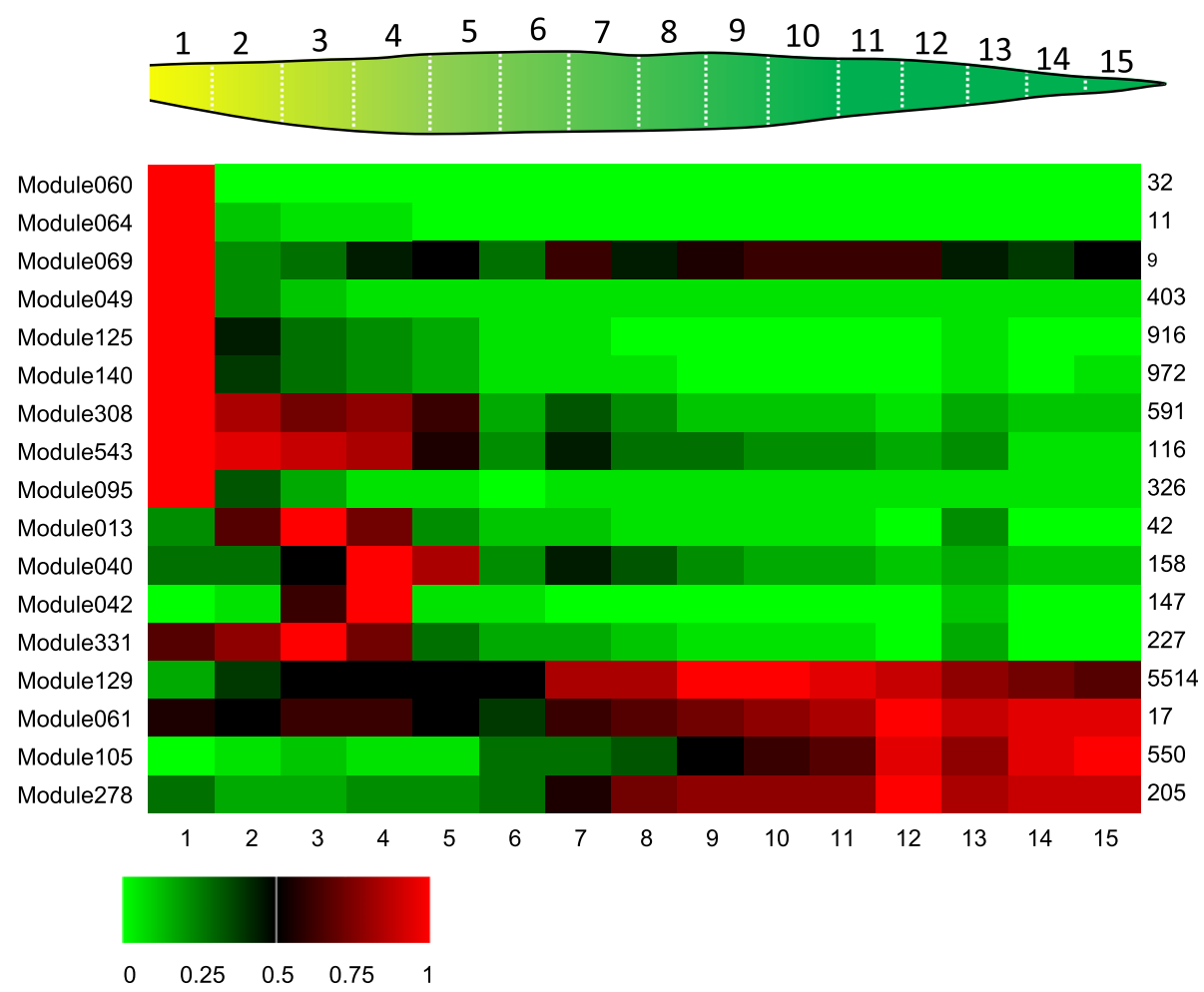

Relative Expression Value

Fig. 7 The average expression level for the genes within selected modules in the maize leaves transcription datasets. On top is a diagram of the 15 leaf segments. In the middle is a heatmap showing the relative expression level of each module in each segments compared to the highest expression level for that module over all segments, as indicated by the number on the right. A legend indicating the relative expression level is shown on the bottom

wide range of maize physiological processes. These modules are particularly useful in that they can assign putative functions to unknown/uncharacterized genes and identify participating genes (including novel genes) for specific developmental or physiological processes, as demonstrated by the selected examples. Module structure and the nature of the genes assembled in a module may then be used to analyze individual gene expression datasets, for example the expression data on maize leaf segments.

The modules identified in our network analysis covered many aspects of maize biology. Compared to a previously published maize transcriptional network that contained 49 modules [6], our model defined 964 modules in total. Sizes of previously identified modules were large. Considering that $87 \%$ of all genes in previous network [6] were included in modules with more than 1000 genes it was difficult to pinpoint potential key regulatory genes as candidates for future studies. In contrast, our GGM network identified modules containing between 5 and 306 genes, which facilitated ranking of potentially interesting genes, as demonstrated by the presentation above for various modules. Also, we were particularly encouraged by the numerous examples in which individual GGM modules identified control genes that had previously been revealed and verified experimentally by mutants analysis, such as $\mathrm{ra1} / 3$ in Module \#16, o2, pbf1 in Module \#46, $b x 1 / 2 / 3 / 4 / 5 / 6 / 8$ in Module \#80, and pl1, $r 1$ in Module \#154 [44, 50, 69, 70, 81, 82]. In an additional contrast to Downs et al. (2013), where the focus on developmental microarray data sets recovered modules with tissue-specific expression, our maize GGM gene network is condition-independent, constructed from transcriptome datasets related to development, stresses, nutrition, as well as other treatments. This facilitated the distinction between modules involved in cell organization, development, nutrients utilization, metabolism, and stress responses. These modules could potentially play critical roles in determining important maize agronomic traits. For example, the inflorescences development related Module \#16 includes 5 genes ral, ba1, $g t 1$, tgal, and $t b 1$ that have been shown by mutants analysis to regulate maize inflorescences architecture, and these 5 genes are designated as domestication genes since they were subjected to selections in the history of maize domestication as they control desirable traits 
$[44,45,47,51,52,56]$, while other genes within this module might also control maize architecture and performance. As well, modules for ligules and kernels development, for nitrogen and phosphate uptake and utilization, for primary and secondary metabolisms, and for responses to fungal infections include a wealth of information potentially useful for crop improvement.

An important feature of our network is that transcription factors and their target genes are often contained within the same module, suggesting shared expression characteristics. One example is the endosperm development Module \#46, which is enriched with zein storage protein genes. The regulatory genes for zein biosynthesis, TF $o 2$ and $p b f 1$, are contained within this modules as well. In yet another example, the master regulator TF of seed maturation, $v p 1$, is included within the seed maturation Module \#6. The ligule-related Module \#48 contains the master regulator gene lg1, encoding a SPL TF. The genes within this module are enriched a SPL binding motif, indicating they are targets of Lg1. Similarly, the heat-induced Module \#10 contains 6 heat shock TF genes hsft7/8/12/20/24, the ER-stress response Module \#95 includes a putative maser regulator bzip60, and the phosphate starvation response Module \#38 possesses three putative master regulator glk4, glk5, glk7. Significantly, many identified modules also included genes encoding unknown and uncharacterized TFs that may represent novel gene expression regulators. The modular structures, as revealed by our network, provide an expedient and edifying way to identify putative TF regulators for various maize pathways.

The maize gene network also enables cross-species comparison between maize and Arabidopsis. The comparison revealed an unexpected degree of insight into different degrees of conservation in different pathways. Not surprisingly, cell organization modules showed the highest percentage of conserved genes, indicating the evolutionary stability of such basic cellular pathways. Among development related modules, those involved in generating basic building blocks of the plant body are shown to be conserved as well, i.e. carpels, Casparian strip, epidermis, and cell walls. However, divergence was found for functions in modules related to the overall architecture of the plants, for example the development of inflorescence structures. Such comparison sheds light on pathways that might have been "hot targets" for evolutionary changes. In the near future, with RNA-Seq transcriptome datasets rapidly accumulating, such network comparison analysis can be extended into more plant species to identify steps that highlight and determine plant evolutionary trajectories. As shown here for maize and Arabidopsis, conversation and similarity in modular comparisons will assist in pinpointing key regulators in various modules that can then be analyzed in detailed studies.

\section{Conclusions}

In conclusion, the maize GGM network presented here in juxtaposition with a corresponding Arabidopsis network [7] - sheds light on similarities and differences in the organization of gene modules between different species in the context of evolutionary separation and different life histories. Additionally, our analysis highlights modules whose structure and gene content can provide important new resources for maize gene functional studies with application potential.

\section{Methods}

\section{Maize RNA-Seq data collection}

The publicly available maize RNA-Seq transcriptome datasets deposited in the NCBI SRA database were used in the analysis. These datasets were organized by studies. The studies were manually inspected to filter out those focusing on non-coding RNAs or those measuring transcriptome of the same tissues from a large number of maize varieties. Also removed were the studies with less than five RNA-Seq runs or without published articles. As a result, 36 studies were kept and their raw data files (sra) were downloaded. For RNA-Seq data processing, adapter sequences, if present, were removed from raw sequence reads using FASTX-toolkit pipeline version 0.0.13 (http://hannonlab.cshl.edu/fastx_toolkit/). Sequence quality was examined using FastQC (http:// www.bioinformatics.babraham.ac.uk/projects/fastqc/), and low quality read was filtered by FASTX-toolkit. The remaining reads were then mapped to the maize genome AGP v3.22 (Ensembl Plants, http://plants.ensembl.org) using Tophat v2.0.10 [97] with default settings. After removing files with mapping rate smaller than $70 \%$, the bam files from 787 RNA-Seq runs were analyzed to obtain gene expression values (FPKM) via Cufflinks v2.1.1 [98].

\section{Maize GGM network construction}

The gene expression data were then merged into a single gene expression matrix with 787 columns, and the low expressed genes (maximum FPKM values among all samples being less than 20) were filtered out, resulting in a matrix with 29,316 genes and 787 columns. The matrix was log-transformed [32-40] via the $\log _{2}$ $($ FPKM +1$)$ function, a procedure that significantly reduced the dataset's mean-variance dependency (Additional file 2: Fig. S1). The log-transformed gene expression matrix was then used for partial correlation calculation, following a method described before [17]. Briefly, the calculation involved a procedure with 25,000 iterations. In each iteration, 2000 genes were randomly 
selected and the partial correlation coefficients between gene pairs were estimated via the "ggm.estimate.pcor" function in the GeneNet v1.2.13 package in R [16]. The Pcors were recorded in every iteration. After 25,000 iterations, for every gene pair, the Pcor with the lowest absolute value was chosen as its final Pcor. The PCC between all gene pairs were also calculated. The gene pairs with Pcor $>=0.035$ and PCC $>=0.35$ and those with Pcor $<=-0.035$ and $\mathrm{PCC}<=-0.35$ were selected for gene network construction (Additional file 2: Table S2), resulting in a maize GGM gene network based on the log-transformed gene expression data.

To evaluate the effect of log-transformation on the network quality, another gene network was also constructed directly from the gene expression matrix with the original FPKM values without data transformation, designated as non-transformed FPKM network, keeping all other parameters the same as in the logtransformation-based network outlined above. These two networks were then evaluated and compared via the EGAD package in $\mathrm{R}$ regarding their capacities to connect maize genes with shared GO terms [99]. The results indicated the log-transformation-based network outperformed the non-transformed FPKM network (Additional file 8: Fig. S9). Additionally, the logtransformation-based network identified gene modules that were not recovered by the non-transformed FPKM network, such as those related to ER stress response (\#95) and nitrate response \& assimilation (\#72) (data not shown). These modules identified only by the logtransformation-based network contained genes that have been identified in different analyses to be related to the modules in question [73, 74, 91, 92].

Thus, we considered the higher power of the logtransformation-based network, and only results using the log-transformation-based network, designated as the Maize GGM Network, were further analyzed and discussed.

\section{Gene network properties and gene module identification}

The R package of RBGL v 1.44.0 (http://bioconductor.org/ packages/RBGL/) is used to calculate the clustering coefficient of the maize GGM network. The network was clustered via the MCL clustering algorithm, using these parameters "-I 1.5 -Scheme 7" [43]. The genes within each module were then analyzed for Gene Ontology enrichment via GOStats [100], with GO annotation file downloaded from the Gramene database (ftp://ftp.gramene.org/). The maize genes and their Arabidopsis homologues were further annotated with annotation files from MaizeGDB, TAIR, and PlnTFDB [101-103]. Selected modules were also tested for promoter motifs enrichment via the binomial distribution. An R script, included in the accompanied program MaizeGGM2016, was developed to extract sub-networks for gene modules and to draw development heatmaps for the genes within selected modules, with expression data from published datasets [19-21, 23-26]. The whole GGM network and the extracted sub-networks were layout and visualized with BioLayout Express 3D and Cytoscape 3.3 , respectively $[104,105]$.

\section{Gene network comparison between the maize network and the Arabidopsis network}

To enable comparison between the maize GGM network and the Arabidopsis network AtGGM2014, the InParanoid program (v 4.1) [106] was used to identify the maize genes', if present, most similar homologues in Arabidopsis. For any gene within the maize network, if there exists a homologous gene within the Arabidopsis AtGGM2014 network, the maize gene's immediate neighboring genes within the maize network were extracted as group A. Also extracted, as group B, were its homologous gene's neighbors within the Arabidopsis network. If any of the gene within group A has a homologous gene in group B, the original maize gene was considered to have conserved interaction within the Arabidopsis network. For any given module, the percentage of genes with conserved interaction was calculated as an indicator of evolution conserveness or divergence.

\section{Additional files}

Additional file 1: Table S1. The RNA-Seq studies used in the analysis. Table S4. Selected gene modules identified from the network. Table S5. The percentage of genes with conserved interactions within each module. (XLSX $45 \mathrm{~kb}$ )

Additional file 2: Figure S1. Log-transformation reduced the meanvariance dependency of the maize RNA-Seq data. a The standard deviation of each gene's non-transformed FPKM expression values across all 787 RNA-seq runs are shown against the rank of genes. Genes are ranked by their mean expression values, from low (left) to high (right). The red line depicts a trend line of standard deviation, which indicates a clear mean-variance dependency. $\mathbf{b}$ The standard deviation of each gene's expression values after log transformation across all RNA-Seq runs against the rank of genes. The mean-variance dependency is greatly reduced. (PDF $5820 \mathrm{~kb}$ )

Additional file 3: Table S2. The 123,666 gene pairs used for the maize GGM gene network construction. (TXT 4378 kb)

Additional file 4: Table S3. The 964 gene modules identified from the network. Listed are the genes' names and their module identity, and the results of gene ontology enrichment analysis. (XLSX $3251 \mathrm{~kb}$ )

Additional file 5: Figure S2. A heatmap showing the tissue-specific gene expression patterns for the inflorescences, ligules, and kernels development related modules. The data source of the SRA studies were labeled in the sample names. Listed are the maize genes names and its symbol in lowercase letters, or, if it has no symbols, the names of its Arabidopsis homologues. (PDF $2927 \mathrm{~kb}$ )

Additional file 6: Figure S3. A heatmap for modules related to endosperm development. (PDF $2005 \mathrm{~kb}$ )

Additional file 7: Figure S4. A heatmap for additional modules related to development. (PDF $4276 \mathrm{~kb}$ ) 
Additional file 8: Figure S5. A module for wax biosynthesis. Figure S6. A module for heat-shock stress response. Figure S7. A module for ER-stress response. Figure S8. A module for stress response to fungus. Figure $\mathbf{S 9}$. Comparison between the non-transformed FPKM network and the logtransformation-based network. Both networks were evaluated via the EGAD package [99] in $\mathrm{R}$ regarding their capacities to connect genes with shared $\mathrm{GO}$ terms. For each $\mathrm{GO}$ term, the maize genes with that $\mathrm{GO}$ were considered as a gene set, and an AUROC value was calculated for each network using the EGAD package. A higher AUROC value indicates genes within that gene set are more likely to have each other as neighbors, and thus a better performance of the network. The histogram shows the overall distribution of the AUROC values for $1728 \mathrm{GO}$ terms calculated for the non-transformed FPKM network (green bar) and for the log-transformation-based network (transparent bar with black border). The log-transformation-based network has more GO terms with higher AUROC values, thus it performs better than the other network. (PDF $795 \mathrm{~kb}$ )

\section{Acknowledgements}

We thank Dr. Hans Bohnert for his critical reading of the manuscript. We are indebted to his invaluable suggestions.

\section{Funding}

S.M. is supported by grants from Thousand Youth Talents Program and University of Science and Technology of China (Start-up fund). P.L. is supported by grants from NSFC (91435108), National Key Research and Development Program of China (2016YFD0101003) and Taishan Scholarship.

\section{Availability of data and materials}

The maize gene network, and a companion program MaizeGGM2016, can be downloaded from our laboratory website for academic usage (http://staff.ustc.edu.cn/ sma/maizeggm.html).

\section{Authors' contributions}

SM and PL designed experiments. SM, ZD, and PL performed experiments. SM and PL wrote and edited the manuscript. All authors read and approved the final manuscript.

\section{Ethics approval and consent to participate} Not applicable.

\section{Consent for publication}

Not applicable.

\section{Competing interests}

The authors declare that they have no competing interests.

\section{Publisher's Note}

Springer Nature remains neutral with regard to jurisdictional claims in published maps and institutional affiliations.

\section{Author details}

${ }^{1}$ School of Life Sciences, University of Science and Technology of China, Hefei, Anhui, China. ${ }^{2}$ The Institute of Tropical Bioscience and Biotechnology, Chinese Academy of Tropical Agricultural Sciences, Haikou, Hainan, China. ${ }^{3}$ State Key Laboratory of Crop Biology, College of Agronomy, Shandong Agricultural University, Tai'an, Shandong, China.

Received: 23 December 2016 Accepted: 19 July 2017 Published online: 01 August 2017

\section{References}

1. Usadel B, Obayashi T, Mutwil M, Giorgi FM, Bassel GW, Tanimoto M, Chow A, Steinhauser D, Persson S, Provart NJ. Co-expression tools for plant biology: opportunities for hypothesis generation and caveats. Plant Cell Environ. 2009;32:1633-51.

2. Obayashi T, Kinoshita K, Nakai K, Shibaoka M, Hayashi S, Saeki M, Shibata D, Saito K, Ohta H. ATTED-II: a database of co-expressed genes and cis elements for identifying co-regulated gene groups in Arabidopsis. Nucleic Acids Res. 2007;35:D863-9.
3. Persson S, Wei H, Milne J, Page GP, Somerville CR. Identification of genes required for cellulose synthesis by regression analysis of public microarray data sets. Proc Natl Acad Sci U S A. 2005;102:8633-8.

4. FANTOM Consortium and the RIKEN PMI and CLST (DGT), Forrest AR, Kawaji $H$, Rehli M, Baillie JK, de Hoon MJ, Haberle V, Lassmann T, et al. A promoter-level mammalian expression atlas. Nature. 2014;507:462-70.

5. Dekkers BJ, Pearce $S$, van Bolderen-Veldkamp RP, Marshall A, Widera P, Gilbert J, Drost HG, Bassel GW, Muller K, King JR, et al. Transcriptional dynamics of two seed compartments with opposing roles in Arabidopsis seed germination. Plant Physiol. 2013;163:205-15.

6. Downs GS, Bi YM, Colasanti J, Wu W, Chen X, Zhu T, Rothstein SJ, Lukens LN. A developmental transcriptional network for maize defines coexpression modules. Plant Physiol. 2013;161:1830-43.

7. Ma S, Bohnert HJ, Dinesh-Kumar SP. AtGGM2014, an Arabidopsis gene coexpression network for functional studies. Sci China Life Sci. 2015:58:276-86.

8. Mao L, Van Hemert JL, Dash S, Dickerson JA. Arabidopsis gene co-expression network and its functional modules. BMC Bioinformatics. 2009:10:346.

9. Mistry M, Gillis J, Pavlidis P. Meta-analysis of gene coexpression networks in the post-mortem prefrontal cortex of patients with schizophrenia and unaffected controls. BMC Neurosci. 2013;14:105.

10. Stuart JM, Segal E, Koller D, Kim SK. A gene-coexpression network for global discovery of conserved genetic modules. Science. 2003;302:249-55.

11. Mentzen WI, Wurtele ES. Regulon organization of Arabidopsis. BMC Plant Biol. 2008;8:99

12. Childs KL, Davidson RM, Buell CR. Gene coexpression network analysis as a source of functional annotation for rice genes. PLoS One. 2011;6:e22196.

13. Ficklin SP, Feltus FA. Gene coexpression network alignment and conservation of gene modules between two grass species: maize and rice. Plant Physiol. 2011;156:1244-56.

14. Zhang B, Horvath S. A general framework for weighted gene co-expression network analysis. Stat Appl Genet Mol Biol 2005;4:Article17.

15. Wille A, Zimmermann P, Vranova E, Furholz A, Laule O, Bleuler S, Hennig L, Prelic A, von Rohr $P$, Thiele $L$, et al. Sparse graphical Gaussian modeling of the isoprenoid gene network in Arabidopsis Thaliana. Genome Biol. 2004;5:R92

16. Schäfer J, Strimmer K. A shrinkage approach to large-scale covariance matrix estimation and implications for functional genomics. Stat Appl Genet Mol Biol 2005;4:Article32.

17. Ma S, Gong Q, Bohnert HJ. An Arabidopsis gene network based on the graphical Gaussian model. Genome Res. 2007:17:1614-25.

18. Zuo Y, Yu G, Tadesse MG, Ressom HW. Biological network inference using low order partial correlation. Methods. 2014;69:266-73.

19. Sekhon RS, Briskine R, Hirsch CN, Myers CL, Springer NM, Buell CR, de Leon N, Kaeppler SM. Maize gene atlas developed by RNA sequencing and comparative evaluation of transcriptomes based on RNA sequencing and microarrays. PLoS One. 2013;8:e61005.

20. Stelpflug SC, Sekhon RS, Vaillancourt B, Hirsch CN, Buell CR, de Leon N, Kaeppler SM: An expanded maize gene expression atlas based on RNA sequencing and its use to explore root development. The Plant Genome 2016;9:0.

21. Eveland AL, Goldshmidt A, Pautler M, Morohashi K, Liseron-Monfils C, Lewis MW, Kumari S, Hiraga S, Yang F, Unger-Wallace E, et al. Regulatory modules controlling maize inflorescence architecture. Genome Res. 2014;24:431-43.

22. Wang L, Czedik-Eysenberg A, Mertz RA, Si Y, Tohge T, Nunes-Nesi A Arrivault S, Dedow LK, Bryant DW, Zhou W, et al. Comparative analyses of $C(4)$ and C(3) photosynthesis in developing leaves of maize and rice. Nat Biotechnol. 2014;32:1158-65.

23. Johnston R, Wang M, Sun Q, Sylvester AW, Hake S, Scanlon MJ. Transcriptomic analyses indicate that maize ligule development recapitulates gene expression patterns that occur during lateral organ initiation. Plant Cell. 2014:26:4718-32.

24. Chen J, Zeng B, Zhang M, Xie S, Wang G, Hauck A, Lai J. Dynamic transcriptome landscape of maize embryo and endosperm development. Plant Physiol. 2014;166:252-64.

25. Yi G, Neelakandan AK, Gontarek BC, Vollbrecht E, Becraft PW. The naked endosperm genes encode duplicate INDETERMINATE domain transcription factors required for maize endosperm cell patterning and differentiation. Plant Physiol. 2015;167:443-56.

26. Zhan J, Thakare D, Ma C, Lloyd A, Nixon NM, Arakaki AM, Burnett WJ, Logan $\mathrm{KO}$, Wang $\mathrm{D}$, Wang $\mathrm{X}$, et al. RNA sequencing of laser-capture 
microdissected compartments of the maize kernel identifies regulatory modules associated with endosperm cell differentiation. Plant Cell. 2015;27:513-31

27. Makarevitch I, Waters AJ, West PT, Stitzer M, Hirsch CN, Ross-Ibarra J, Springer NM. Transposable elements contribute to activation of maize genes in response to abiotic stress. PLoS Genet. 2015;11:e1004915.

28. Ding Y, Virlouvet L, Liu N, Riethoven JJ, Fromm M, Avramova Z. Dehydration stress memory genes of Zea Mays; comparison with Arabidopsis Thaliana. BMC Plant Biol. 2014;14:141.

29. Lanubile A, Ferrarini A, Maschietto V, Delledonne M, Marocco A, Bellin D. Functional genomic analysis of constitutive and inducible defense responses to Fusarium verticillioides infection in maize genotypes with contrasting ear rot resistance. BMC Genomics. 2014;15:710.

30. Bi YM, Meyer A, Downs GS, Shi X, El-Kereamy A, Lukens L, Rothstein SJ. High throughput RNA sequencing of a hybrid maize and its parents shows different mechanisms responsive to nitrogen limitation. BMC Genomics. 2014;15:77.

31. Walley JW, Sartor RC, Shen Z, Schmitz RJ, Wu KJ, Urich MA, Nery JR, Smith LG, Schnable JC, Ecker JR, Briggs SP. Integration of omic networks in a developmental atlas of maize. Science. 2016;353:814-8.

32. Zwiener I, Frisch B, Binder H. Transforming RNA-Seq data to improve the performance of prognostic gene signatures. PLoS One. 2014;9:e85150.

33. Specht AT, Li J. LEAP: constructing gene co-expression networks for single-cell RNA-sequencing data using pseudotime ordering. Bioinformatics. 2017;33:764-6.

34. Israel JW, Martik ML, Byrne M, Raff EC, Raff RA, McClay DR, Wray GA. Comparative developmental Transcriptomics reveals rewiring of a highly conserved gene regulatory network during a major life history switch in the sea urchin genus Heliocidaris. PLoS Biol. 2016;14:e1002391.

35. Kim B, Suo B, Emmons SW. Gene function prediction based on developmental Transcriptomes of the two sexes in C. Elegans. Cell Rep. 2016;17:917-28.

36. Pfeifer M, Kugler KG, Sandve SR, Zhan B, Rudi H, Hvidsten TR, International Wheat Genome Sequencing C, Mayer KF, Olsen OA. Genome interplay in the grain transcriptome of hexaploid bread wheat. Science. 2014;345:1250091.

37. Sekhon RS, Hirsch CN, Childs KL, Breitzman MW, Kell P, Duvick S, Spalding EP, Buell CR, de Leon N, Kaeppler SM. Phenotypic and transcriptional analysis of divergently selected maize populations reveals the role of developmental timing in seed size determination. Plant Physiol. 2014;165:658-69.

38. Fertuzinhos S, Li M, Kawasawa YI, Ivic V, Franjic D, Singh D, Crair M, Sestan N. Laminar and temporal expression dynamics of coding and noncoding RNAs in the mouse neocortex. Cell Rep. 2014;6:938-50.

39. Xiao X, Moreno-Moral A, Rotival M, Bottolo L, Petretto E. Multi-tissue analysis of co-expression networks by higher-order generalized singular value decomposition identifies functionally coherent transcriptional modules. PLoS Genet. 2014;10:e1004006.

40. Langfelder P, Horvath S: WGCNA package FAQ. https://labs.genetics.ucla. edu/horvath/CoexpressionNetwork/Rpackages/WGCNA/faq.html. Accessed 11 May 2017.

41. Watts DJ, Strogatz SH. Collective dynamics of 'small-world' networks. Nature 1998:393:440-2

42. Ravasz E, Somera AL, Mongru DA, Oltvai ZN, Barabasi AL. Hierarchical organization of modularity in metabolic networks. Science. 2002;297:1551-5.

43. van Dongen S. Graph clustering by flow simulation. Dissertation: University of Utrecht; 2000

44. Vollbrecht E, Springer PS, Goh L, Buckler ES, Martienssen R. Architecture of floral branch systems in maize and related grasses. Nature. 2005;436:1119-26.

45. Gallavotti A, Zhao Q, Kyozuka J, Meeley RB, Ritter MK, Doebley JF, Pe ME, Schmidt RJ. The role of barren stalk1 in the architecture of maize. Nature. 2004:432:630-5.

46. Chuck G, Muszynski M, Kellogg E, Hake S, Schmidt RJ. The control of spikelet meristem identity by the branched silkless 1 gene in maize. Science. 2002;298:1238-41.

47. Doebley J, Stec A, Hubbard L. The evolution of apical dominance in maize. Nature. 1997;386:485-8.

48. Gallavotti A, Barazesh S, Malcomber S, Hall D, Jackson D, Schmidt RJ McSteen P. Sparse inflorescence1 encodes a monocot-specific YUCCA-like gene required for vegetative and reproductive development in maize. Proc Natl Acad Sci U S A. 2008;105:15196-201.
49. Hayward AP, Moreno MA, Howard TP 3rd, Hague J, Nelson K, Heffelfinger C, Romero S, Kausch AP, Glauser G, Acosta IF, et al. Control of sexuality by the sk1-encoded UDP-glycosyltransferase of maize. Sci Adv. 2016;2:e1600991.

50. Satoh-Nagasawa N, Nagasawa N, Malcomber S, Sakai H, Jackson D. A trehalose metabolic enzyme controls inflorescence architecture in maize. Nature. 2006:441:227-30

51. Whipple CJ, Kebrom TH, Weber AL, Yang F, Hall D, Meeley R, Schmidt R, Doebley J, Brutnell TP, Jackson DP. Grassy tillers1 promotes apical dominance in maize and responds to shade signals in the grasses. Proc Natl Acad Sci U S A. 2011;108:E506-12.

52. Wang H, Nussbaum-Wagler T, Li B, Zhao Q, Vigouroux Y, Faller M, Bomblies K, Lukens L, Doebley JF. The origin of the naked grains of maize. Nature. 2005;436:714-9.

53. Karim MR, Hirota A, Kwiatkowska D, Tasaka M, Aida M. A role for Arabidopsis PUCHI in floral meristem identity and bract suppression. Plant Cell. 2009;21:1360-72.

54. Klucher KM, Chow H, Reiser L, Fischer RL. The AINTEGUMENTA gene of Arabidopsis required for ovule and female gametophyte development is related to the floral homeotic gene APETALA2. Plant Cell. 1996;8:137-53.

55. Vroemen CW, Mordhorst AP, Albrecht C, Kwaaitaal MA, de Vries SC. The CUP-SHAPED COTYLEDON3 gene is required for boundary and shoot meristem formation in Arabidopsis. Plant Cell. 2003;15:1563-77.

56. Swanson-Wagner R, Briskine R, Schaefer R, Hufford MB, Ross-lbarra J, Myers $C L$, Tiffin P, Springer NM. Reshaping of the maize transcriptome by domestication. Proc Natl Acad Sci U S A. 2012;109:11878-83.

57. Becraft PW, Bongard-Pierce DK, Sylvester AW, Poethig RS, Freeling M. The liguleless-1 gene acts tissue specifically in maize leaf development. Dev Biol. 1990;141:220-32.

58. Moreno MA, Harper LC, Krueger RW, Dellaporta SL, Freeling M. Liguleless1 encodes a nuclear-localized protein required for induction of ligules and auricles during maize leaf organogenesis. Genes Dev. 1997;11:616-28.

59. Birkenbihl RP, Jach G, Saedler H, Huijser P. Functional dissection of the plant-specific SBP-domain: overlap of the DNA-binding and nuclear localization domains. J Mol Biol. 2005:352:585-96.

60. Lee DK, Geisler M, Springer PS. LATERAL ORGAN FUSION1 and LATERAL ORGAN FUSION2 function in lateral organ separation and axillary meristem formation in Arabidopsis. Development. 2009;136:2423-32.

61. Jaillais Y, Hothorn M, Belkhadir Y, Dabi T, Nimchuk ZL, Meyerowitz EM, Chory J. Tyrosine phosphorylation controls brassinosteroid receptor activation by triggering membrane release of its kinase inhibitor. Genes Dev. 2011;25:232-7.

62. Wang H, Zhu Y, Fujioka S, Asami T, Li J. Regulation of Arabidopsis brassinosteroid signaling by atypical basic helix-loop-helix proteins. Plant Cell. 2009;21:3781-91.

63. Kir G, Ye H, Nelissen H, Neelakandan AK, Kusnandar AS, Luo A, Inze D, Sylvester AW, Yin Y, Becraft PW. RNA interference knockdown of BRASSINOSTEROID INSENSITIVE1 in maize reveals novel functions for Brassinosteroid signaling in controlling plant architecture. Plant Physiol. 2015:169:826-39.

64. Becraft PW, Freeling M. Genetic analysis of rough sheath1 developmental mutants of maize. Genetics. 1994:136:295-311.

65. Fowler JE, Freeling M. Genetic analysis of mutations that alter cell fates in maize leaves: dominant Liguleless mutations. Dev Genet. 1996;18:198-222.

66. Foster T, Yamaguchi J, Wong BC, Veit B, Hake S. Gnarley1 is a dominant mutation in the knox4 Homeobox gene affecting cell shape and identity. Plant Cell. 1999;11:1239-52.

67. Giroux MJ, Boyer C, Feix G, Hannah LC. Coordinated transcriptional regulation of storage product genes in the maize endosperm. Plant Physiol. 1994;106:713-22.

68. Beatty MK, Rahman A, Cao H, Woodman W, Lee M, Myers AM, James MG. Purification and molecular genetic characterization of ZPU1, a pullulanase-type starch-debranching enzyme from maize. Plant Physiol. 1999;119:255-66.

69. Hartings H, Maddaloni M, Lazzaroni N, Di Fonzo N, Motto M, Salamini F, Thompson $\mathrm{R}$. The $\mathrm{O} 2$ gene which regulates zein deposition in maize endosperm encodes a protein with structural homologies to transcriptional activators. EMBO J. 1989;8:2795-801.

70. Vicente-Carbajosa J, Moose SP, Parsons RL, Schmidt RJ. A maize zinc-finger protein binds the prolamin box in zein gene promoters and interacts with the basic leucine zipper transcriptional activator Opaque2. Proc Natl Acad Sci U S A. 1997;94:7685-90. 
71. McCarty DR, Carson CB, Stinard PS, Robertson DS. Molecular analysis of viviparous-1: an Abscisic acid-insensitive mutant of maize. Plant Cell. 1989;1:523-32.

72. Xu G, Fan X, Miller AJ. Plant nitrogen assimilation and use efficiency. Annu Rev Plant Biol. 2012;63:153-82.

73. Lahners K, Kramer V, Back E, Privalle L, Rothstein S. Molecular cloning of complementary DNA encoding maize nitrite reductase: molecular analysis and nitrate induction. Plant Physiol. 1988;88:741-6.

74. sakakibara H, Kawabata S, Takahashi H, Hase T, Sugiyama T. Molecular Cloning of the Family of Glutamine Synthetase Genes from Maize: Expression of Genes for Glutamine Synthetase and Ferredoxin-Dependent Glutamate Synthase in Photosynthetic and Non-Photosynthetic Tissues. Plant Cell Physiol. 1992;33:49-58.

75. Ho CH, Lin SH, Hu HC, Tsay YF. CHL1 functions as a nitrate sensor in plants. Cell. 2009;138:1184-94.

76. De Angeli A, Monachello D, Ephritikhine G, Frachisse JM, Thomine S, Gambale F, Barbier-Brygoo H. The nitrate/proton antiporter AtCLCa mediates nitrate accumulation in plant vacuoles. Nature. 2006:442:939-42.

77. Rubin G, Tohge T, Matsuda F, Saito K, Scheible WR. Members of the LBD family of transcription factors repress anthocyanin synthesis and affect additional nitrogen responses in Arabidopsis. Plant Cell. 2009;21:3567-84.

78. Hammond JP, Bennett MJ, Bowen HC, Broadley MR, Eastwood DC, May ST, Rahn C, Swarup R, Woolaway KE, White PJ. Changes in gene expression in Arabidopsis shoots during phosphate starvation and the potential for developing smart plants. Plant Physiol. 2003;132:578-96.

79. Rubio V, Linhares F, Solano R, Martin AC, Iglesias J, Leyva A, Paz-Ares J. A conserved MYB transcription factor involved in phosphate starvation signaling both in vascular plants and in unicellular algae. Genes Dev. 2001;15:2122-33.

80. Tzin V, Fernandez-Pozo N, Richter A, Schmelz EA, Schoettner M, Schafer M, Ahern KR, Meihls LN, Kaur H, Huffaker A, et al. Dynamic maize responses to aphid feeding are revealed by a time series of Transcriptomic and Metabolomic assays. Plant Physiol. 2015;169:1727-43.

81. Frey M, Schullehner K, Dick R, Fiesselmann A, Gierl A. Benzoxazinoid biosynthesis, a model for evolution of secondary metabolic pathways in plants. Phytochemistry. 2009;70:1645-51

82. Petroni K, Pilu R, Tonelli C. Anthocyanins in corn: a wealth of genes for human health. Planta. 2014:240:901-11.

83. Johnson CS, Kolevski B, Smyth DR. TRANSPARENT TESTA GLABRA2, a trichome and seed coat development gene of Arabidopsis, encodes a WRKY transcription factor. Plant Cell. 2002;14:1359-75.

84. Goodman CD, Casati P, Walbot V. A multidrug resistance-associated protein involved in anthocyanin transport in Zea Mays. Plant Cell. 2004;16:1812-26.

85. Post-Beittenmiller D. Biochemistry and molecular biology of wax production in plants. Annu Rev Plant Physiol Plant Mol Biol. 1996;47:405-30.

86. Lee SB, Suh MC. Advances in the understanding of cuticular waxes in Arabidopsis Thaliana and crop species. Plant Cell Rep. 2015;34:557-72.

87. La Rocca N, Manzotti PS, Cavaiuolo M, Barbante A, Dalla Vecchia F, Gabotti D, Gendrot G, Horner DS, Krstajic J, Persico M, et al. The maize fused leaves1 (fdl1) gene controls organ separation in the embryo and seedling shoot and promotes coleoptile opening. J Exp Bot. 2015;66:5753-67.

88. Lee SB, Suh MC. Cuticular wax biosynthesis is up-regulated by the MYB94 transcription factor in Arabidopsis. Plant Cell Physiol. 2015:56:48-60.

89. Liu S, Yeh CT, Tang HM, Nettleton D, Schnable PS. Gene mapping via bulked segregant RNA-Seq (BSR-Seq). PLoS One. 2012;7:e36406.

90. Baud S, Wuilleme S, To A, Rochat C, Lepiniec L. Role of WRINKLED1 in the transcriptional regulation of glycolytic and fatty acid biosynthetic genes in Arabidopsis. Plant J. 2009;60:933-47.

91. Kirst ME, Meyer DJ, Gibbon BC, Jung R, Boston RS. Identification and characterization of endoplasmic reticulum-associated degradation proteins differentially affected by endoplasmic reticulum stress. Plant Physiol. 2005;138:218-31.

92. Li Y, Humbert S, Howell SH. ZmbZIP60 mRNA is spliced in maize in response to ER stress. BMC Research Notes. 2012;5:144.

93. Iwata Y, Fedoroff NV, Koizumi N. Arabidopsis bZIP60 is a proteolysisactivated transcription factor involved in the endoplasmic reticulum stress response. Plant Cell. 2008;20:3107-21.

94. Saga H, Ogawa T, Kai K, Suzuki H, Ogata Y, Sakurai N, Shibata D, Ohta D. Identification and characterization of ANAC042, a transcription factor family gene involved in the regulation of camalexin biosynthesis in Arabidopsis. Mol Plant-Microbe Interact. 2012;25:684-96.
95. Skibbe DS, Doehlemann G, Fernandes J, Walbot V. Maize tumors caused by Ustilago Maydis require organ-specific genes in host and pathogen. Science. 2010;328:89-92.

96. Li P, Ponnala L, Gandotra N, Wang L, Si Y, Tausta SL, Kebrom TH, Provart N, Patel R, Myers CR, et al. The developmental dynamics of the maize leaf transcriptome. Nat Genet. 2010;42:1060-7.

97. Trapnell C, Pachter L, Salzberg SL. TopHat: discovering splice junctions with RNA-Seq. Bioinformatics. 2009;25:1105-11.

98. Trapnell C, Roberts A, Goff L, Pertea G, Kim D, Kelley DR, Pimentel H, Salzberg SL, Rinn JL, Pachter L. Differential gene and transcript expression analysis of RNA-seq experiments with TopHat and cufflinks. Nat Protoc. 2012;7:562-78.

99. Ballouz S, Weber M, Pavlidis P, Gillis J. EGAD: ultra-fast functional analysis of gene networks. Bioinformatics. 2017;33:612-14.

100. Falcon S, Gentleman R. Using GOstats to test gene lists for GO term association. Bioinformatics. 2007;23:257-8.

101. Andorf CM, Cannon EK, Portwood JL 2nd, Gardiner JM, Harper LC, Schaeffer ML, Braun BL, Campbell DA, Vinnakota AG, Sribalusu W, et al. MaizeGDB update: new tools, data and interface for the maize model organism database. Nucleic Acids Res. 2016;44:D1195-201.

102. Lamesch P, Berardini TZ, Li D, Swarbreck D, Wilks C, Sasidharan R, Muller R, Dreher K, Alexander DL, Garcia-Hernandez M, et al. The Arabidopsis information resource (TAIR): improved gene annotation and new tools. Nucleic Acids Res. 2012;40:D1202-10.

103. Perez-Rodriguez P, Riano-Pachon DM, Correa LG, Rensing SA, Kersten B, Mueller-Roeber B. PInTFDB: updated content and new features of the plant transcription factor database. Nucleic Acids Res. 2010;38:D822-7.

104. Shannon P, Markiel A, Ozier O, Baliga NS, Wang JT, Ramage D, Amin N, Schwikowski B, Ideker T. Cytoscape: a software environment for integrated models of biomolecular interaction networks. Genome Res. 2003;13:2498-504.

105. Theocharidis A, van Dongen S, Enright AJ, Freeman TC. Network visualization and analysis of gene expression data using BioLayout express(3D). Nat Protoc. 2009;4:1535-50

106. Sonnhammer EL, Ostlund G. InParanoid 8: orthology analysis between 273 proteomes, mostly eukaryotic. Nucleic Acids Res. 2015;43:D234-9.

\section{Submit your next manuscript to BioMed Central and we will help you at every step:}

- We accept pre-submission inquiries

- Our selector tool helps you to find the most relevant journal

- We provide round the clock customer support

- Convenient online submission

- Thorough peer review

- Inclusion in PubMed and all major indexing services

- Maximum visibility for your research

Submit your manuscript at www.biomedcentral.com/submit
C) Biomed Central 